\title{
Development of Non-insulin-dependent Diabetes Mellitus in the Double Knockout Mice with Disruption of Insulin Receptor Substrate-1 and $\beta$ Cell Glucokinase Genes

\author{
Genetic Reconstitution of Diabetes as a Polygenic Disease
}

\begin{abstract}
Yasuo Terauchi, ${ }^{\star}$ Keiji Iwamoto, ${ }^{*}$ Hiroyuki Tamemoto, ${ }^{\star}$ Kajuro Komeda, ${ }^{\ddagger}$ Chikara Ishii,§ Yasunori Kanazawa," Nahoko Asanuma," Toru Aizawa," Yasuo Akanuma, ${ }^{* \star}$ Kazuki Yasuda, ${ }^{, \star}$ Tatsuhiko Kodama, ${ }^{\star \ddagger}$ Kazuyuki Tobe, ${ }^{*}$ Yoshio Yazaki, ${ }^{\star}$ and Takashi Kadowaki ${ }^{\star}$

*Third Department of Internal Medicine, Faculty of Medicine, University of Tokyo, 7-3-1 Hongo, Bunkyo-ku, Tokyo 113, Japan; ${ }^{\ddagger}$ Division of Laboratory Animal Science, Animal Research Center, Tokyo Medical College, Shinjuku-ku, Tokyo 160, Japan; ${ }^{\S}$ Fourth Department of Internal Medicine, Saitama Medical School, Moroyama 350-04, Japan; Omiya Medical Center, Jichi Medical School, Omiya 330, Japan; ${ }^{\llbracket}$ Department of Geriatrics, Shinshu University School of Medicine, Matsumoto 390, Japan; **Institute for Diabetes Care and Research, Asahi Life Foundation, Chiyoda-ku, Tokyo 100, Japan; ${ }^{\ddagger}$ Research Center for Advanced Science and Technology, University of Tokyo, Meguro-ku, Tokyo 153, Japan
\end{abstract}

\section{Abstract}

Non-insulin-dependent diabetes mellitus (NIDDM) is considered a polygenic disorder in which insulin resistance and insulin secretory defect are the major etiologic factors. Homozygous mice with insulin receptor substrate-1 (IRS-1) gene knockout showed normal glucose tolerance associated with insulin resistance and compensatory hyperinsulinemia. Heterozygous mice with $\beta$ cell glucokinase (GK) gene knockout showed impaired glucose tolerance due to decreased insulin secretion to glucose. To elucidate the interplay between insulin resistance and insulin secretory defect for the development of NIDDM, we generated double knockout mice with disruption of IRS-1 and $\beta$ cell GK genes by crossing the mice with each of the single gene knockout. The double knockout mice developed overt diabetes. Blood glucose levels $120 \mathrm{~min}$ after intraperitoneal glucose load (1.5 mg/g body wt) were $108 \pm 24$ (wild type), $95 \pm 26$ (IRS-1 knockout), 159 \pm 68 (GK knockout), and $210 \pm 38$ (double knockout) $\mathrm{mg} / \mathrm{dl}($ mean $\pm \mathrm{SD}$ ) (double versus wild type, IRS-1, or GK; $P<0.01$ ). The double knockout mice showed fasting hyperinsulinemia and selective hyperplasia of the $\beta$ cells as the IRS-1 knockout mice (fasting insulin levels: $0.38 \pm 0.30$ [double knockout], $0.35 \pm 0.27$ [IRS-1 knockout] versus $0.25 \pm 0.12$ [wild type] $\mathrm{ng} / \mathrm{ml}$ ) (proportion of areas of insulin-positive cells to the pancreas: $1.18 \pm 0.68 \% ; P<0.01$ [double knockout], $1.20 \pm 0.93 \% ; P<$ 0.05 [IRS-1 knockout] versus $0.54 \pm 0.26 \%$ [wild type]), but impaired insulin secretion to glucose (the ratio of increment of insulin to that of glucose during the first 30 min after load: 31 [double knockout] versus 163 [wild type] or 183 [IRS-1 knockout] ng insulin/mg glucose $\times 10^{3}$ ). In conclusion, the genetic abnormalities, each of which is nondiabeto-

Address correspondence to Takashi Kadowaki, M.D., Third Department of Internal Medicine, Faculty of Medicine, The University of Tokyo, 7-3-1 Hongo, Bunkyo-ku, Tokyo 113, Japan. Phone: 81-33815-5411 ext. 3111; FAX: 81-3-5689-7209.

Received for publication 7 October 1996 and accepted in revised form 9 December 1996.

J. Clin. Invest.

(C) The American Society for Clinical Investigation, Inc.

0021-9738/97/03/0861/06 \$2.00

Volume 99, Number 5, March 1997, 861-866 genic by itself, cause overt diabetes if they coexist. This report provides the first genetic reconstitution of NIDDM as a polygenic disorder in mice. (J. Clin. Invest. 1997. 99:861866.) Key words: insulin receptor substrate-1 - glucokinase • non-insulin-dependent diabetes mellitus • insulin resistance • insulin secretory dysfunction

\section{Introduction}

Non-insulin-dependent diabetes mellitus (NIDDM) ${ }^{1}$ is characterized by peripheral insulin resistance and insulin secretory dysfunction $(1,2)$. These abnormalities are either genetically defined or augmented by hyperglycemia itself, and may interact in a complex manner to cause and sustain hyperglycemia. Previous prospective studies have demonstrated that both insulin resistance/hyperinsulinemia and low insulin response to glucose are predictors of NIDDM (3-7). To investigate the interactions between insulin resistance and insulin secretory defect in the development of diabetes, we generated an animal model with two defined genetic defects which caused insulin resistance and impaired insulin secretion to glucose by crossing insulin receptor substrate- 1 (IRS-1) deficient mice $(8,9)$ and $\beta$ cell glucokinase (GK) deficient mice (10).

IRS-1 deficient mice showed normal glucose tolerance despite insulin resistance due to compensatory hyperinsulinemia (8). When IRS-1 deficient mice were genetically crossed with heterozygous $\beta$ cell GK deficient mice which showed nonprogressive glucose intolerance due to impaired insulin response to glucose (10), the double knockout mice developed diabetes. These results are consistent with the concept that increased insulin resistance and decreased insulin secretion are independent yet cooperative risk factors for the development of NIDDM.

To our knowledge, this is the first report to reconstitute NIDDM, which is a polygenic disease, by manipulating individual genetic defects such as insulin resistance and insulin secretory dysfunction in mice. The information obtained and the strategy used in this research should be of relevance to the analysis of pathogenesis of human NIDDM and other polygenic diseases.

1. Abbreviations used in this paper: GK, glucokinase; IRS-1, insulin receptor substrate-1; NIDDM, non-insulin-dependent diabetes mellitus. 


\section{Methods}

Creation of animal models and mouse husbandry. Mice lacking IRS-1 or pancreatic $\beta$ cell GK were generated as described $(8,10)$. Since homozygous mutant mice for the GK gene were perinatally lethal due to defective insulin secretion to glucose, we intended to create mice lacking IRS-1 homozygously and GK heterozygously. Heterozygous mutants for the GK gene $\left(G K^{+/-}\right)(129 \times$ ICR background $)(10)$ were crossed with homozygous mutants for the IRS-1 gene (IRS-1 $\left.1^{-1-}\right)$ $\left(\mathrm{C} 57 \mathrm{BL} / 6 \times \mathrm{CBA}\right.$ background) $(8)$, which generated $\mathrm{GK}^{+/+} \mathrm{IRS}-1^{+/-}$ and $G K^{+/-} I R S-1^{+/-} . G K^{+/-} I R S-1^{+l-}$ were crossed with IRS-1 $1^{-1-}$ or wild type of the C57BL/6 background, which yielded six genotypes of mice: $G K^{+/+} I R S-1^{+/+}, G K^{+/+} I R S-1^{+/-}, G K^{+/+} I R S-1^{-/-}, G K^{+/-} I R S-1^{+/+}$, $G K^{+/-} I R S-1^{+/-}$, and $G K^{+/-} I R S-1^{-1-}$, all of which had the same genetic background $(129 \times \mathrm{ICR} \times \mathrm{C} 57 \mathrm{BL} / 6 \times \mathrm{CBA})$. Among six genotypes generated, four were used for the following experiments: $G K^{+/+} I R S-1^{+/+}, G^{+/+} I R S-1^{-/-}, G K^{+/-} I R S-1^{+/+}$, and $G K^{+/-} I R S-1^{-/-}$. Mice were bred on normal chow and maintained using standard husbandry procedures. The animal care and procedures were approved by the Animal Care Committee of University of Tokyo.

Genotyping by PCR. The genotype of the mice was determined by PCR. The genomic DNA was extracted from the tail tip. Primers and PCR conditions for genotyping of the IRS-1 gene were described in reference 8 . For genotyping of the GK gene, the sense primer was 5'-CACCTGGTTGGAACAGAAGC-3', and the antisense primers were 5'-ATGTGGAATGTGTGCGAGGC-3' derived from a neomycin resistance gene driven by a pgk-1 promoter, and 5'-TTGGTGGCCTCCATCCTGGC-3' derived from the GK gene. Three primers and genomic DNA template were mixed in a tube. The thermal cycle reaction consisted of $94^{\circ} \mathrm{C}$ for $5 \mathrm{~min}$, followed by 35 cycles of $94^{\circ} \mathrm{C}$ $(1 \mathrm{~min}), 60^{\circ} \mathrm{C}(1 \mathrm{~min}), 72^{\circ} \mathrm{C}(1 \mathrm{~min})$, and $72^{\circ} \mathrm{C}(5 \mathrm{~min})$. The wild type allele gave $450 \mathrm{bp}$, and the recombinant allele gave $250 \mathrm{bp}$.

Glucose tolerance test. Male mice (30-40 wk of age) were fasted for more than $16 \mathrm{~h}$ before the study. They were then loaded with 1.5 $\mathrm{mg} \mathrm{g}^{-1}$ (body weight) glucose by intraperitoneal infusion. Blood samples were taken at different time points from the tail vein. Insulin levels were determined using an insulin RIA kit (Shionogi Co. Ltd., Osaka, Japan) with rat insulin as standard. Diabetic glucose tolerance was defined as fasting and/or $120 \mathrm{~min}$ blood glucose levels higher than three standard deviations above the average levels in the wild type mice. Normal glucose tolerance was defined as fasting, $60 \mathrm{~min}$, and 120 min blood glucose levels lower than one standard deviation above the average. When glucose tolerance was neither diabetic nor normal, it was defined as impaired glucose tolerance.

Insulin tolerance test. Male mice (40-50 wk of age) were fed freely and then fasted during the study. They were intraperitoneally challenged with $0.75 \mathrm{mU} \mathrm{g}^{-1}$ (body weight) human insulin (Novolin $\mathrm{R}$; Novo Nordisk, Denmark). Blood samples were drawn at different time points from the tail vein.

Immunohistochemistry. Pancreata were removed from 30-40 wk-old mice that had been killed by decapitation and immersionfixed in Bouin's solution at $4^{\circ} \mathrm{C}$ overnight. Tissues were routinely processed for paraffin embedding and $4 \mu \mathrm{m}$ sections were cut and mounted on silanized slides. The sections were immunologically stained with diluted guinea pig antiporcine insulin (1:200), using an Envision Labeled Polymer Kit (both from DAKO Japan Co., Ltd., Kyoto, Japan) with a DAB Substrate Kit (3,3'-diaminobenzidine) (Vector Laboratories, Inc., Burlingame, CA).

Estimation of $\beta$ and non- $\beta$ cell mass in the pancreas. Sections were double immunostained with both guinea pig anti porcine insulin (1:200) and mixtures of rabbit anti porcine glucagon (1:200) and human anti-somatostatin (all from DAKO Japan Co., Ltd.) (1:600) antibodies as described (11). The relative volume of $\beta$ cells or non- $\beta$ cells to pancreas was calculated as the proportion of total area of $\beta$ cells or non- $\beta$ cells to that of pancreatic tissues according to the method of Bouwens et al. (12). In brief, figures of pancreatic tissues, islet $\beta$ cells, or islet non- $\beta$ cells were captured on a monitor screen of a Macintosh computer (Apple Co., Ltd., Cupertino, CA) through a microscope connected to a CCD camera (Olympus Co., Ltd., Tokyo, Japan) as described (11). Total areas of pancreatic tissues, islet $\beta$ cells, or islet non- $\beta$ cells were traced manually and those dimensions were analyzed with NIH Image 1.60 software (NIH). The areas of $\beta$ cells, non- $\beta$ cells, and pancreas were determined by counting $\sim 200$ islets or more per mouse in respective groups.

Perifusion and batch-incubation experiments. Pancreatic islets derived from 30-40 wk-old mice were obtained by collagenase dispersion, and insulin release by the islets was determined as described (13, 14) in perifusion and batch-incubation experiments using KrebsRinger bicarbonate buffer; in brief, 50 islets/column and five islets/ tube were used, respectively. The islets were exposed to $3 \mathrm{mM}$ glucose for more than $2 \mathrm{~h}$, and then exposed to $16.7 \mathrm{mM}$ of glucose in perifusion and the indicated concentrations of glucose in batch-incubation, respectively. After measurement, insulin content assays were conducted by acid-ethanol method (10).

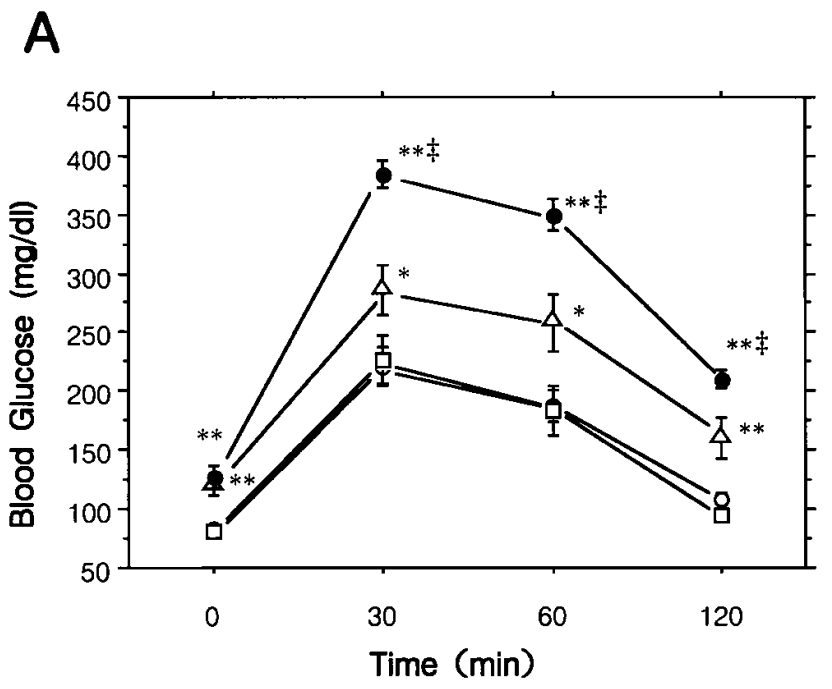

B

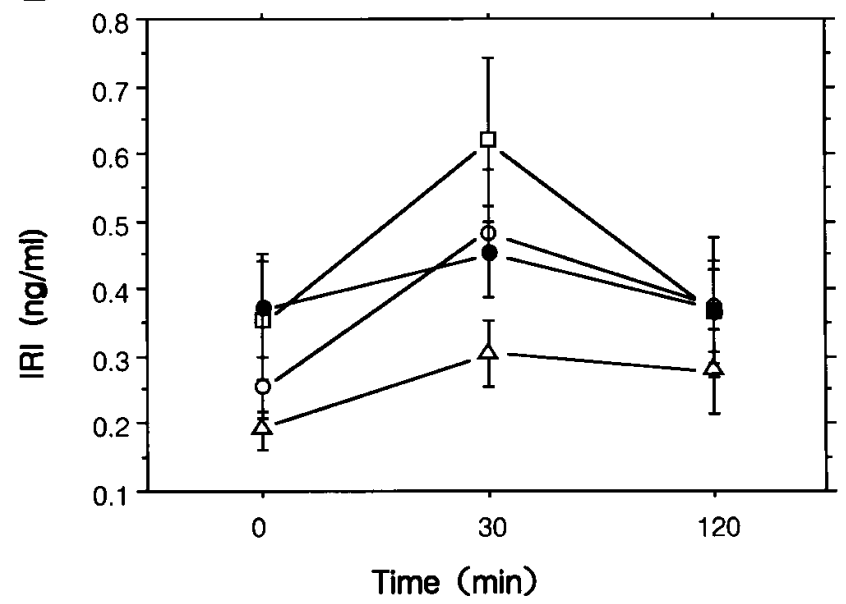

Figure 1. Glucose tolerance test. Wild type mice (open circles) $(n=15)$, $\mathrm{GK}^{+/+}$IRS- $1^{-/-}$(open squares) $(n=16), \mathrm{GK}^{+/-}$IRS- $1^{+/+}$(open triangles $)(n=15)$ and $\mathrm{GK}^{+/-}$IRS- $1^{-/-}$(filled circles) $(n=23)$ were fasted for more than $16 \mathrm{~h}$ before the study. They were then loaded with 1.5 $\mathrm{mg} \mathrm{g}^{-1}$ (body weight) glucose by intraperitoneal infusion. Profiles of blood glucose levels $(A)$ and insulin levels $(B)$ in 30-40 wk-old mice are shown. Results are shown as mean \pm SEM. *Indicates $P<0.05$, ** Indicates $P<0.01$ compared with wild type. Indicates $P<0.01$ compared with $\mathrm{GK}^{+/-}$IRS $-1^{+/+}$. 
Data presentation and statistical methods. Results are expressed as means \pm standard deviation in the text, and as means \pm standard error in the figures. Differences were analyzed using Student's $t$ test. $P$ value $<0.05$ was considered statistically significant.

\section{Results}

Four genotypes of mice were generated: wild type $\left(G K^{+/+} I R S\right.$ $\left.1^{+/+}\right)$, homozygous mutants for the IRS-1 gene $(8,9)\left(G K^{+/+}\right.$ IRS $\left.-1^{-/-}\right)$, heterozygous mutants for the $\beta$ cell glucokinase gene (10) $\left(G K^{+/-} I R S-1^{+/+}\right)$, and double knockout mutants which were homozygous mutant for the IRS- 1 gene and heterozygous mutant for the GK gene $\left(G K^{+1-} I R S-1^{-1-}\right)$, all of which had the same genetic background $(129 \times$ ICR $\times$ C57BL/6 $\times$ CBA). Each genotype was confirmed by the PCR method (data not shown). $G K^{+/+} I R S-1^{-/-}$showed growth retardation as described (8), and the body weight was about $70 \%$ of that of the wild type throughout life. $G K^{+/-} I R S-1^{-1-}$ showed a similar degree of growth retardation as $G K^{+/+} I R S-1^{-1-}$.

Blood glucose levels and serum insulin levels were measured after intraperitoneal glucose load in these mice when they were $30-40 \mathrm{wk}$ of age (Fig. 1). $G K^{+/+} I R S-1^{-/-}$showed normal glucose tolerance. Although not statistically significant, they showed elevated insulin levels: $139 \%$ and $129 \%$ of that in the wild type at fasting and 30 min after a glucose load, respectively, which confirmed our previous report (8). Thus, insulin resistance in these mice is compensated by increased insulin secretion from pancreatic $\beta$ cells. $G K^{+/-} I R S-1^{+/+}$showed impaired glucose tolerance because of decreased insulin secretion to glucose, which was $39 \%$ of that in the wild type in $\Delta \mathrm{I} 30$ / $\Delta \mathrm{G} 30$ (the ratio of increment of insulin to that of glucose during the first $30 \mathrm{~min}$ after load). $G K^{+/-} I R S-1^{-1-}$ exhibited diabetic glucose tolerance, indicating the exacerbation of glucose intolerance in the double-knockout mice as compared with $G K^{+/-} I R S-1^{+/+} . G K^{+/-} I R S-1^{-/-}$exhibited higher, although not statistically significant, insulin level at fasting, which was $148 \%$ of the wild type. However, they showed decreased $\Delta \mathrm{I} 30 / \Delta \mathrm{G} 30$, which was only $19 \%$ of that in the wild type, or only $17 \%$ of that in $G K^{+/+} I R S-1^{-/-}$. At 15 wk of age $G K^{+/-} I R S-1^{-/-}$exhibited similar glucose intolerance to $G K^{+/-} I R S-1^{+/+}$, indicating that the exacerbation of glucose intolerance in the doubleknockout mice might be dependent on age. Insulin loading test revealed that decrease in glucose levels was significantly less in $G K^{+/+} I R S-1^{-1-}$ than in wild type and in $G K^{+/-} I R S-1^{-1-}$ than in $G K^{+/-} I R S-1^{+/+}$, respectively (data not shown), indicating that introduction of $I R S-1^{-1-}$ genotype induced insulin resistance in both wild type and $G K^{+/-}$.

Next, we investigated the histological changes of pancreatic islets. Histological examination revealed that some islets were enlarged in $G K^{+/+} I R S-1^{-/-}$and $G K^{+/-} I R S-1^{-/-}$, while there were no significant morphological alterations in $G K^{+/-} I R S-1^{+/+}$ (Fig. 2). The $\beta$ cell mass per pancreas was $221 \%$ in $G K^{+/+} I R S$ $1^{-1-}(P<0.05), 69 \%$ in $G K^{+/-} I R S-1^{+/+}$, (NS), and $216 \%$ in $G K^{+/-} I R S-1^{-1-}(P<0.01)$ of that in the wild type in terms of area (Fig. 3). In contrast, the non- $\beta$ ( $\alpha$ and $\delta$ ) cell mass was not altered in any of these groups. Interestingly, insulin-positive
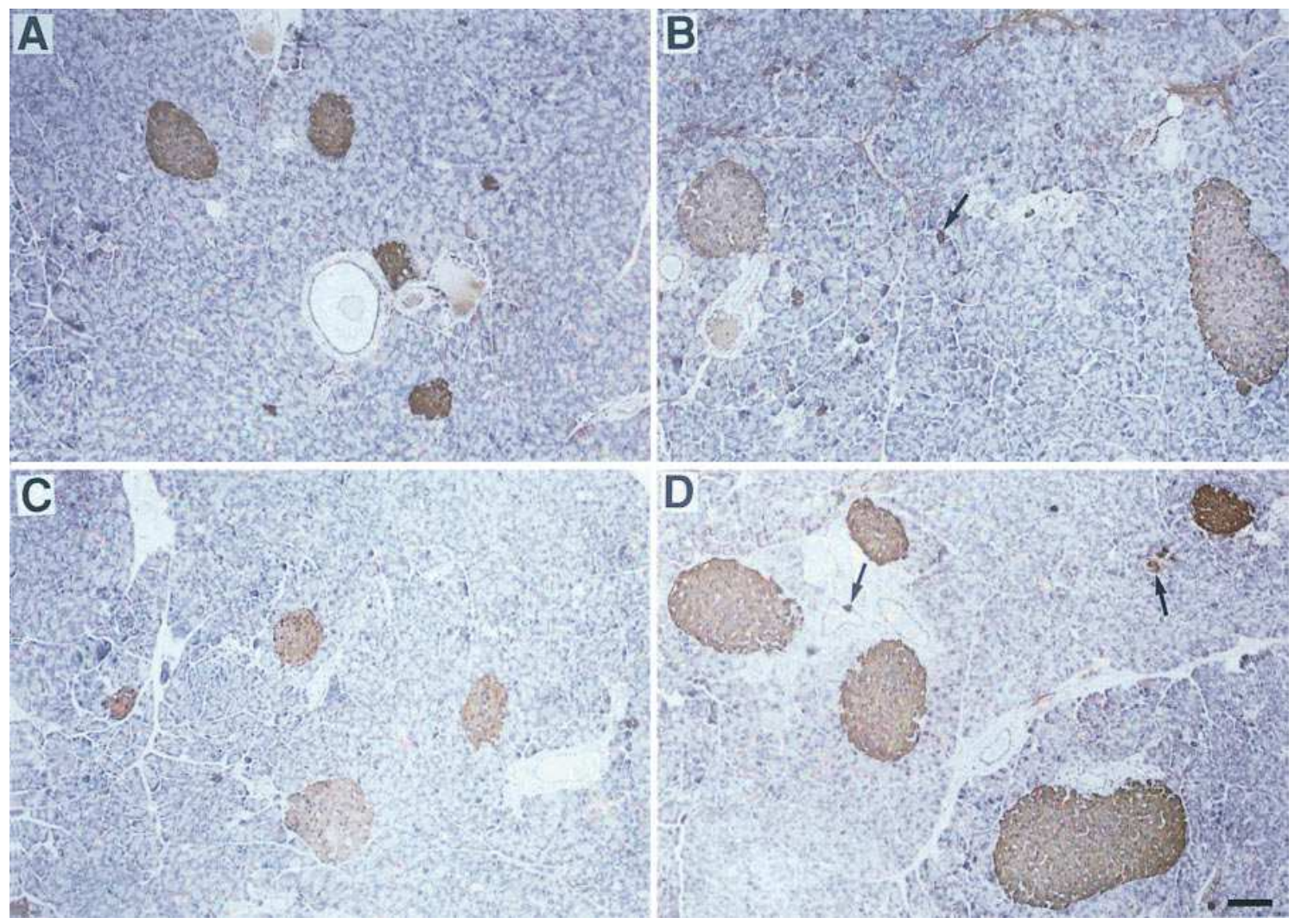

Figure 2. Immunohistochemistry of the islets. Islets were stained for insulin. $(A)$ wild type. $(B) \mathrm{GK}^{+/+} \mathrm{IRS}-1^{-/-}$. $(C) \mathrm{GK}{ }^{+/-}$IRS-1 $1^{+/+}$. (D) $\mathrm{GK}^{+/-} \mathrm{IRS}-1^{-1-}$. Bar, $100 \mu \mathrm{m}$. Insulin-positive cells were detected in $B$ and $D$ in the exocrine tissues or the epithelial cells of the pancreatic duct (arrowheads). 


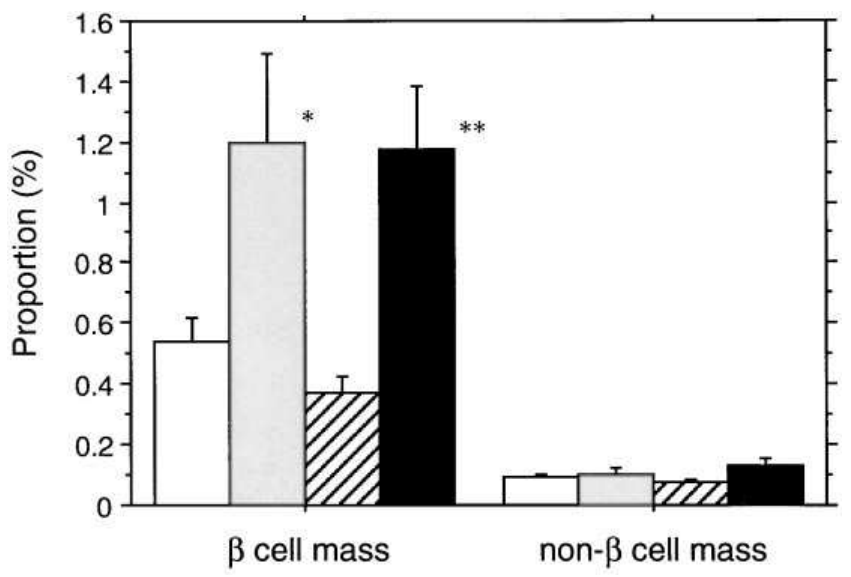

Figure 3. The proportion of $\beta$ cell and non- $\beta$ cell to the pancreas. Pancreatic sections were double-stained with antiinsulin, and the mixture of anti-glucagon and anti-somatostatin antibodies. The area of $\beta$ cell, non- $\beta$ cell ( $\alpha$ cell plus $\delta$ cell), and the pancreas was calculated in computer-treated imaging. More than 200 islets per mouse were scanned. Results are shown in proportion to the pancreas (\%). Unfilled bars: wild type, $(n=4)$; grey bars, $\mathrm{GK}^{+/+} \mathrm{IRS}-1^{-1-}(n=4)$; hatched bars, $\mathrm{GK}^{+/-} \mathrm{IRS}-1^{+/+}(n=4)$; and solid bars, $\mathrm{GK}^{+/-} \mathrm{IRS}-1^{-1-}$ $(n=4)$. *Indicates $P<0.05$, **Indicates $P<0.01$ compared with wild type.

cells were detected even in the exocrine tissues or the epithelial cells of the pancreatic duct and small islets were also increased in the specimen, suggesting the possibility that $\beta$ cell differentiation and neogenesis had been induced from the nonendocrine tissues in $G K^{+/+} I R S-1^{-/-}$and $G K^{+/-} I R S-1^{-1-}$.

In order to assess whether hyperinsulinemia in vivo is caused mainly by $\beta$ cell hyperplasia in $G K^{+/+} I R S-1^{-1-}$ islets, we carried out perifusion and batch-incubation studies of islets from wild type and $G K^{+/+} I R S-1^{-1-}$. When we used islets of similar size, insulin secretion from $G K^{+/+} I R S-1^{-/-}$islets was not significantly different from wild type islets in either the first-phase or the second-phase in perifusion experiments at $16.7 \mathrm{mM}$ glucose (Fig. 4). Furthermore, glucose sensitivity was

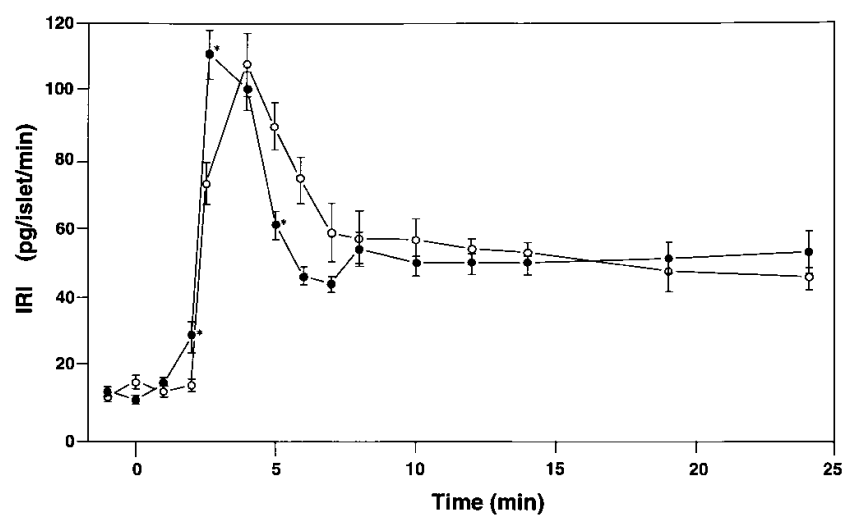

Figure 4. Insulin release by the islets in response to $16.7 \mathrm{mM}$ glucose. The islets were exposed to $16.7 \mathrm{mM}$ glucose after a 30-min prewash with $3 \mathrm{mM}$ glucose. Unfilled circles, the islets from wild type mice $(n=6)$; filled circles, those from $\mathrm{GK}^{+/+} \mathrm{IRS}-1^{-1-}(n=7)$. Results are shown as mean \pm SEM. *Indicates $P<0.05$ compared with wild type.

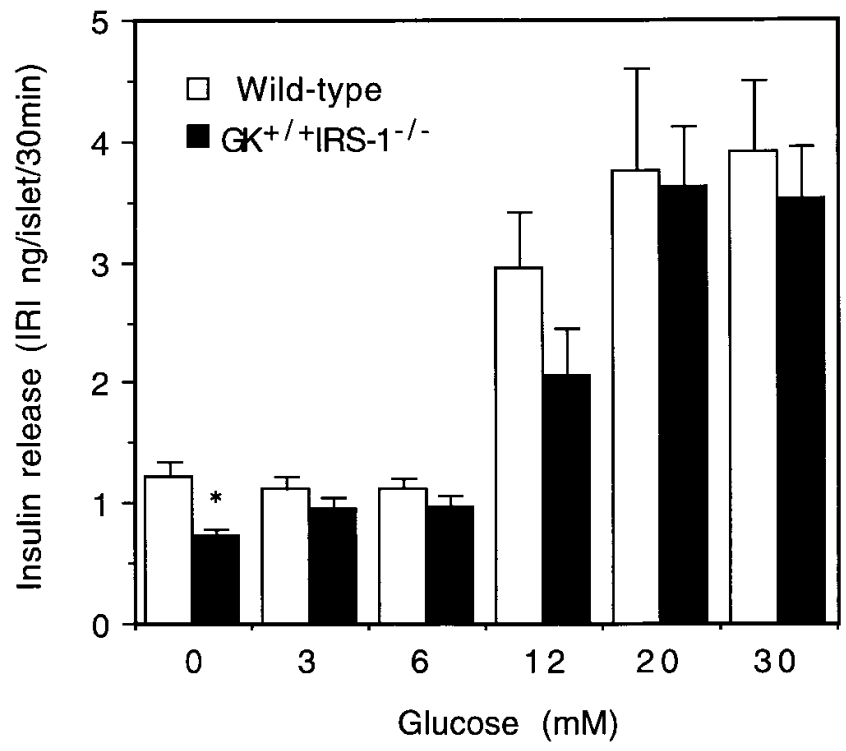

Figure 5. Insulin release by the islets in response to various concentrations of glucose. The islets were exposed to the indicated concentration after a $2 \mathrm{~h}$ prewash with $3 \mathrm{mM}$ glucose. Insulin content was $154 \pm 9 \mathrm{ng} /$ islet $(n=8)$ in the wild type and $146 \pm 9 \mathrm{ng} /$ islet $(n=19)$ in $G K^{+/+} I R S-1^{-1-}$ islet, respectively. Unfilled bars, the islets from wild type mice $(n=7)$; filled bars, those from $\mathrm{GK}^{+/+} \mathrm{IRS}-1^{-1-}(n=7)$. Results are shown as mean \pm SEM. *Indicates $P<0.05$ compared with wild type.

essentially unaltered in $G K^{+/+} I R S-1^{-/-}$islets in batch-incubation experiments (Fig. 5).

\section{Discussion}

To elucidate the interplay between insulin resistance and insulin secretory defect for the development of NIDDM, we generated double knockout mice with disruption of IRS- 1 and $\beta$ cell GK genes by crossing the mice with each of the single gene knockout. IRS-1 knockout mice $\left(G K^{+/+} I R S-1^{-/-}\right)$are characterized by insulin resistance $(8,9)$. We have recently shown that this resistance is a result of defects in insulin actions in the muscles rather than in the liver (15). Despite insulin resistance, $G K^{+/+} I R S-1^{-/-}$showed normal glucose tolerance presumably because of compensatory hyperinsulinemia from the pancreatic $\beta$ cells (Fig. 1). Histologically, they exhibited $\beta$ cell hyperplasia accompanied by partial differentiation of nonendocrine tissues into insulin-positive cells (Figs. 2 and 3). Insulin secretory profile and glucose sensitivity of insulin secretion were indistinguishable between wild type and IRS-1 knockout mice when the same amounts of islets were compared (Figs. 4 and $5)$. Thus, moderate insulin resistance appeared to induce hyperplasia and neogenesis of pancreatic $\beta$ cells rather than $\beta$ cell hyperfunction leading to moderate increase in fasting and postprandial insulin levels in vivo. Since these mice were not associated with hyperglycemia, it seems possible that factor(s) related to insulin resistance other than glucose were also involved in these changes in the pancreatic $\beta$ cells. Whatever the mechanism(s), the observed communication between insulin resistance and $\beta$ cell hyperplasia and differentiation may be of relevance to $\beta$ cell compensation in human prediabetic pa- 
tients who are best characterized by muscle insulin resistance and minimally impaired glucose tolerance because of compensatory hyperinsulinemia from pancreatic $\beta$ cells. Thus, IRS-1 deficient mice provide an excellent animal model for normoglycemic insulin resistance seen in the prediabetic stage of human NIDDM.

Heterozygous $\beta$ cell glucokinase knockout mice $\left(G K^{+/-}\right.$ $I R S-1^{+/+}$) showed impaired glucose tolerance because of decreased insulin secretion to glucose. These mice were not resistant to insulin (data not shown). Despite normal morphology and $\beta$ cell mass (Figs. 2 and 3), insulin secretion from $G K^{+/-}$ $I R S-1^{+/+}$islets was decreased in the perifusion experiments, and was $22 \%$ and $13 \%$ of that in the wild type during the first phase and second phase, respectively (16). Perifusion study of insulin-treated $G K^{+/-} I R S-1^{+/+}$islets revealed that decreased insulin secretion was not secondary to hyperglycemia (16). Thus, a $50 \%$ reduction in the $\beta$ cell glucokinase caused impaired glucose tolerance but not diabetes in the absence of insulin resistance in this mouse background.

$G K^{+/-} I R S-1^{-1-}$ showed significantly higher glucose levels after a glucose load than did $G K^{+/-} I R S-1^{+/+}$or $G K^{+/+} I R S-1^{-/-}$ (Fig. 1), indicating that insulin resistance and insulin secretory defect played a cooperative role in the development and exacerbation of diabetes, even though neither was strong enough alone to cause overt diabetes. From another point of view, even if genetically determined insulin resistance itself might not be sufficient for the development of diabetes, insulin resistance results in diabetes if pancreatic $\beta$ cell function is impaired genetically (this study) or nongenetically. Development of diabetes in the double-knockout mice appears to be agedependent, since this phenomenon was not observed at younger ages (data not shown). At present, we cannot differentiate whether this age-dependent exacerbation of glucose intolerance is due to exhaustion of $\beta$ cells by their continuous exposure to insulin resistance or glucose toxicity. Nevertheless, since $G K^{+/-} I R S-1^{+/+}$did not show any age-dependent exacerbation of glucose tolerance unlike $G K^{+1-} I R S-1^{-1-}$ even though they were similarly glucose intolerant at younger ages (data not shown), $\beta$ cell exhaustion might be involved in the development of diabetes in the double-knockout mice. These animals provided direct evidence for the cooperative role of insulin resistance and insulin secretory defect in the development of NIDDM in mice.

Human NIDDM is a polygenic disease requiring the interactions of multiple genetic factors and environmental factors for its development. However, genetic dissection of NIDDM in humans has been limited both for practical and ethical reasons. In this respect, use of inbred animal models such as GK rat (17) and OLETF rat (18) that spontaneously reproduce the main features of NIDDM is an important strategy for genetic investigations. In this study we employed a novel strategy to reconstitute a polygenic model of NIDDM by crossing individually defined genetic defects. These two strategies share similar advantages in that the interactions of genetic defects as well as those between genetic and environmental factors can be studied in multifactorial traits such as $\operatorname{NIDDM}(19,20)$. Nevertheless, since actual genetic defects have not yet been identified in spontaneous NIDDM animal models $(19,20)$, interpretations of crossing studies are much more straightforward in genetic reconstitution models of this disease. More importantly, since whole genome mapping and identification of human NIDDM genes are progressing rapidly $(21,22)$, the ge- netic reconstitution of defects in human NIDDM genes in mice based upon the strategy used here should give important insight into the molecular mechanism and actual biochemical pathways of human NIDDM.

\section{Acknowledgments}

We would like to thank Ms. C. Hashimura, Ms. Y. Muto, and Mr. S. Chiyonobu for their excellent technical assistance and mouse husbandry.

This work was supported by grant 192125 from the Juvenile Diabetes Foundation International (to T. Kadowaki) and by a grant for diabetes research from the Ohtsuka Pharmaceutical Co., Ltd. (to T. Kadowaki).

\section{References}

1. Taylor, S.I., D. Accili, and Y. Imai. 1994. Insulin resistance or insulin deficiency: which is the primary cause of NIDDM? Diabetes. 43:735-740.

2. Polonsky, K.S., J. Sturis, and G.I. Bell. 1996. Non-insulin-dependent diabetes mellitus-A genetically programmed failure of the beta cell to compensate for insulin resistance. N. Engl. J. Med. 334:777-783.

3. Lillioja, S., D.M. Mott, M. Spraul, R. Ferraro, J.E. Foley, E. Ravussin, W.C. Knowler, P.H. Bennett, and C. Bogardus. 1993. Insulin resistance and insulin secretory dysfunction as precursors of non-insulin-dependent diabetes mellitus: prospective studies of Pima Indians. N. Engl. J. Med. 329:1988-1992.

4. Martin, B.C., J.H. Warram, A.S. Krolewski, R.N. Bergman, J.S. Soeldner, and C.R. Kahn. 1992. Role of glucose and insulin resistance in the development of type 2 diabetes mellitus: results of a 25-year follow-up study. Lancet ( $N$. Am. Ed.). 340:925-929.

5. Kadowaki, T., Y. Miyake, R. Hagura, Y. Akanuma, H. Kajinuma, N. Kuzuya, F. Takaku, and K. Kosaka. 1984. Risk factors for worsening to diabetes in subjects with impaired glucose tolerance. Diabetologia. 26:44-49.

6. Johnston, C., W.K. Ward, J.C. Beard, B. McKnight, and D. Porte, Jr. 1990. Islet function and insulin sensitivity in the non-diabetic offspring of conjugal type 2 diabetic patients. Diabetic Med. 7:119-125.

7. Haffner, S.M., H. Miettinen, S.P. Gaskill, and M.P. Stern. 1995. Decreased insulin secretion and increased insulin resistance are independently related to the 7-year risk of NIDDM in Mexican-Americans. Diabetes. 44:13861391.

8. Tamemoto, H., T. Kadowaki, K. Tobe, T. Yagi, H. Sakura, T. Hayakawa, Y. Terauchi, K. Ueki, Y. Kaburagi, S. Satoh, et al. 1994. Insulin resistance and growth retardation in mice lacking insulin receptor substrate-1. Nature (Lond.). 372:182-186.

9. Araki, E., M.A. Lipes, M.E. Patti, J.C. Bruning, B. Haag III, R.S. Johnson, and C.R. Kahn. 1994. Alternative pathway of insulin signaling in mice with targeted disruption of the IRS-1 gene. Nature (Lond.). 372:186-190.

10. Terauchi, Y., H. Sakura, K. Yasuda, K. Iwamoto, N. Takahashi, K. Ito, H. Kasai, H. Suzuki, O. Ueda, N. Kamada, et al. 1995. Pancreatic- $\beta$ cell specific targeted disruption of glucokinase gene: diabetes mellitus due to defective insulin secretion to glucose. J. Biol. Chem. 268:30253-30256.

11. Ishii, C., S. Kawazu, T. Utsugi, Y. Ito, T. Ohno, N. Kato, M. Shimizu, S. Tomono, R. Nagai, and K. Komeda. 1996. Beta-cell replication in insulin-induced remission of IDDM in BB/Wor//Tky rats. Diabetes Res. 31:1-18.

12. Bouwens, L., R.N. Wang, E. De-Blay, D.G. Pipeleers, and G. Kloppel. 1994. Cytokeratins as markers of ductal cell differentiation and islet neogenesis in neonatal rat pancreas. Diabetes. 43:1279-1283.

13. Sato, Y., T. Aizawa, M. Komatsu, N. Okada, and T. Yamada. 1992. Dual functional role of membrane depolarization $/ \mathrm{Ca}^{2+}$ influx in rat pancreatic B-cell. Diabetes. 41:438-443.

14. Aizawa, T., Y. Sato, F. Ishihara, M. Komatsu, N. Taguchi, K. Hashizume, and T. Yamada. 1994. ATP-sensitive $\mathrm{K}^{+}$channel-independent glucose action in rat pancreatic $\beta$-cell. Am. J. Physiol. 266:C622-C627.

15. Yamauchi, T., K. Tobe, H. Tamemoto, K. Ueki, Y. Kaburagi, R. Yamamoto-Honda, Y. Takahashi, F. Yoshizawa, S. Aizawa, N. Sonenberg, et al. 1996. Insulin signaling and insulin actions in the muscles and livers of insulinresistant, insulin receptor substrate 1-deficient mice. Mol. Cell. Biol. 16:30743084 .

16. Aizawa, T., N. Asanuma, Y. Terauchi, N. Suzuki, M. Komatsu, N. Itoh, T. Nakabayashi, H. Hidaka, H. Ohnota, K. Yamauchi, et al. 1996. Analysis of the pancreatic $\beta$ cell in the mouse with targeted disruption of the pancreatic $\beta$ cell-specific glucokinase gene. Biochem. Biophys. Res. Commun. 229:460-465.

17. Kimura, K., T. Toyota, M. Kakizaki, M. Kudo, K. Takebe, and Y. Goto. 1981. Impaired insulin secretion in the spontaneous diabetic rats. Tohoku J. Exp. Med. 137:453-459.

18. Kawano, K., T. Hirashima, S. Mori, Y. Saitoh, M. Kurosumi, and T. Na- 
tori. 1992. Spontaneous long-term hyperglycemic rat with diabetic complications. Otsuka Long-Evans Tokushima Fatty (OLETF) strain. Diabetes. 41: 1422-1428.

19. Galli, J., L-S. Li, A. Glaser, C.-G. Östenson, H. Jiao, H. Fakhrai-Rad, H.J. Jacob, E.S. Lander, and H. Luthman. 1996. Genetic analysis of non-insulin dependent diabetes mellitus in the GK rat. Nat. Genet. 12:31-37.

20. Gauguier, D., P. Froguel, V. Parent, C. Bernard, M-T. Bihoreau, B. Portha, M.R. James, L. Penicaud, M. Lathrop, and A. Ktorza. 1996. Chromosomal mapping of genetic loci associated with non-insulin dependent diabetes in the GK rat. Nat. Genet. 12:38-43.
21. Hanis, C.L., E. Boerwinkle, R. Chakraborty, D.L. Ellsworth, P. Concannon, B. Stirling, V.A. Morrison, B. Wapelhorst, R.S. Spielman, K.J. Gogolin-

Ewens, et al. 1996. A genome-wide search for human non-insulin-dependent (type2) diabetes genes reveals a major susceptibility locus on chromosome 2. Nat. Genet. 13:161-166.

22. Melanie, M.M., E. Widen, M. Lehto, J. Thomas, M. McCarthy, J. Brayer, B. Bryant, G. Chan, M. Daly, C. Forsbolm, et al. 1996. Mapping of a gene for type 2 diabetes associated with an insulin secretion defect by a genome scan in Finnish families. Nat. Genet. 14:90-94. 